\title{
Towards a learning path specification
}

\author{
Citation for published version (APA):
}

Janssen, J., Berlanga, A., Vogten, H., \& Koper, R. (2008). Towards a learning path specification. International Journal of Continuing Engineering Education and Life-Long Learning, 18(1), 77-97.

https://doi.org/10.1504/IJCEELL.2008.016077

\section{DOI:}

10.1504/IJCEELL.2008.016077

Document status and date:

Published: 01/01/2008

Document Version:

Peer reviewed version

\section{Document license:}

CC BY-NC-SA

Please check the document version of this publication:

- A submitted manuscript is the version of the article upon submission and before peer-review. There can be important differences between the submitted version and the official published version of record. People interested in the research are advised to contact the author for the final version of the publication, or visit the DOI to the publisher's website.

- The final author version and the galley proof are versions of the publication after peer review.

- The final published version features the final layout of the paper including the volume, issue and page numbers.

Link to publication

\section{General rights}

Copyright and moral rights for the publications made accessible in the public portal are retained by the authors and/or other copyright owners and it is a condition of accessing publications that users recognise and abide by the legal requirements associated with these rights.

- Users may download and print one copy of any publication from the public portal for the purpose of private study or research.

- You may not further distribute the material or use it for any profit-making activity or commercial gain

- You may freely distribute the URL identifying the publication in the public portal.

If the publication is distributed under the terms of Article 25fa of the Dutch Copyright Act, indicated by the "Taverne" license above, please follow below link for the End User Agreement:

https://www.ou.nl/taverne-agreement

Take down policy

If you believe that this document breaches copyright please contact us at:

pure-support@ou.nl

providing details and we will investigate your claim.

Downloaded from https://research.ou.nl/ on date: 26 Apr. 2023 


\title{
Towards a learning path specification
}

\author{
José Janssen, Adriana Berlanga, Hubert Vogten, Rob Koper
}

\begin{abstract}
Flexible lifelong learning requires comparability and exchangeability of courses, programmes and other types of learning actions both in a national and international context. This paper argues that in order to achieve comparability and exchangeability a uniform and meaningful way to describe learning paths towards attainment of learning outcomes is needed. The paper identifies the requirements for a learning path specification drawing on a study of literature in the field of curriculum design and lifelong learning, and on recent initiatives which aimed to enhance comparability and exchangeability of learning actions. Two existing specifications designed to describe learning programmes, XCRI and IMS-LD, are investigated to see whether they can fulfil the identified requirements. The fact that IMS-LD has a generic way to define completion of learning paths as well as an expression language to describe all kinds of conditions make IMS-LD a more likely candidate. A learning path model is presented identifying the main elements of a learning path specification and mapping them on IMS-LD.
\end{abstract}

\section{Introduction}

Notions like the "European area of higher education" (Bologna-Declaration, 1999) or “a European area of lifelong learning” (CEC, 2001) are still merely concepts rather than realities, although quite some progress has been made exploring ways to start realising easy exchange of courses and programs across national and institutional borders (CEC, 2004; González \& Wagenaar, 2003; PLOTEUS, 2006; Pöyry, Pelto-Aho, \& Puustjärvi, 2002; TENCompetence, 2005). Apart from the aim of improving the mobility of employees across Europe, the idea is to enhance flexible lifelong learning by removing barriers to the exchange of programs, courses, and other educational offerings which in this paper will all be called learning actions. Exchangeability is an attribute of the relation between learning actions indicating that one action can be substituted or replaced by another, simply because they result in similar learning outcomes or because they result in learning outcomes which are formally recognised (certified) as a valid alternative within a wider programme. To establish whether or not learning actions are exchangeable they have to be described in a way that they can be compared at least on the main variable in this definition: learning outcomes or competences. If two learning actions lead to the same competences at comparable levels this information might suffice to conclude they are exchangeable. However other factors might be included in the equation, like the amount of effort the learning action requires, previous studies, and formal recognition (Pöyry, Pelto-Aho, \& Puustjärvi, 2002; Ramos, Kautonen, \& Keller, 2001). On a more prosaic level a learner might find a course cannot simply be replaced by another due to all kinds of possible constraints (e.g. time, costs). Information on these and possibly other characteristics have to be provided to enable lifelong learners to compare learning actions and select those that best match their needs.

In formal education the aim to create a European area of higher education has led to calls for an "over-arching European credit accumulation and transfer framework that can make system intelligible to system” (Adam, 2001). Most European higher education systems have witnessed reforms leading to greater convergence of qualification structures in the wake of the Bologna Declaration. Despite a broad adoption and use of the European Credit Transfer System (ECTS), the desired transparency and convergence of higher education systems still hasn't been achieved (Adam, 2001; Karran, 2004). Apart from difficulties stemming from different deployment of the system, true transparency would require that credits gained from different types and levels of educational experience are clearly labelled, identified and understood.

An additional challenge lies in the fact that in lifelong learning the learner might perform formal, non-formal and informal learning actions in parallel: take a job-related training course 
at work, retrieve information from the Internet and study for a master's degree at a university in the evening. Instead of the addressing the problem of exchangeability by agreeing on structures and formats for exchange beforehand, we would like to facilitate exchange of learning actions which are not necessarily developed within agreed upon curricular contexts. Regarding lifelong learning the concept of Learning Networks (LN's) has been introduced (Koper, Rusman, \& Sloep, 2005; Koper \& Tattersall, 2004). LN’s are envisaged to facilitate a broad variety of learning opportunities in a particular domain, covering both formal and nonformal learning, both emergent and pre-planned learning actions. Given this broad variety of learning actions, a learner in a Learning Network may achieve the same learning outcomes by following different learning paths. Consequently learners will need navigational support in identifying alternatives and finding an optimal way to achieve the learning outcomes. For learners to be self-directed, they need an overview of available learning actions that fit their learning needs, preferences, and prior-knowledge. Figure 1 illustrates the concept of a Learning Network. The small nodes in the Learning Network represent learning outcomes a learner might want to attain in this particular domain, "competence A" for instance. The learner in figure 1 aims towards the long term goal of acquiring competence profile X, e.g. a basic level in nursing or an 'advanced level' in playing acoustic guitar, that includes competences I, U, M, R, Q, A, G. A competence profile describes the set of competences and proficiency levels needed to perform adequately in a particular job, function or role.

The learner profile represents the competences already acquired by the learner. In figure 1 the learner already has acquired some competences in the domain ( $\mathrm{H}, \mathrm{D}, \mathrm{K}$, and $\mathrm{R})$. These might have been attained within the Learning Network or through acknowledgement of prior learning (APL). At any rate part of competence profile X, namely competence R, already has been mastered. Apart from the overlap between the learner profile and the competence profile, overlap might exist between different competence profiles as the figure illustrates:

competence profile $\mathrm{W}$ and $\mathrm{X}$ share competence U. Competences related to life aid for instance will be relevant for both the competence profile of a nurse and a doctor.

To the extent that a competence consists of different proficiency levels this is modelled within the competence node rather than through separate nodes for each level. We assume dependencies exist between competences, but these are not modelled, but rather derived from dependencies expressed at the level of learning actions. We will return to this issue later on.

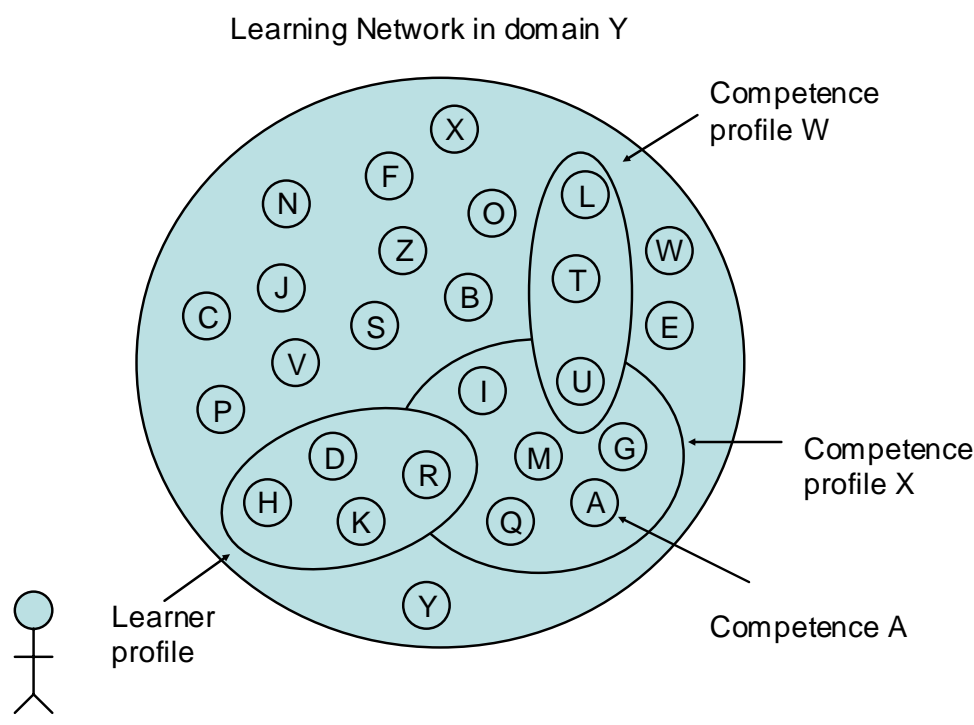

Figure 1 Lifelong learner in a Learning Network 
The learning goal of a learner might vary from acquiring a single competence to an entire competence profile. Some support might be needed for the learner to 'translate' learning goals to competences and competence profiles.

Once a competence or competence profile has been selected the question arises how best to work towards that learning outcome, i.e. which learning path to follow. A learning path that covers more than one competence is called an extended learning path. First of course the learner profile has to be taken into account: checks have to be made for possible overlap between competences in the competence profile and the learner profile. Apart from the learner profile, the 'best' way will depend on various characteristics which will not be equally relevant to all learners. Characteristics most evidently affecting the choice for a learning path are for instance costs, delivery mode (distance teaching or face-to-face), and scheduling. Ideally, information about learning outcomes and learning actions should be amenable to automatic processing, thereby enabling learning brokerages or software agents to intermediate between learners and learning providers to identify the most appropriate steps to be taken at any point in a learning lifetime (TENCompetence, 2005). However the selection and decision processes regarding appropriate learning paths is unlikely to become fully automated, simply because some human interpretation is likely to remain needed, for instance regarding the descriptions of the contents, learning strategies, etc. Nevertheless some automated filtering could be applied, offering learners the possibility to indicate for instance cost ranges, start and end dates, weekly study load etc. To support such filtering learning paths must be described in a uniform and meaningful way. This paper will investigate the requirements for a learning path specification: what aspects of learning, learning actions and learning paths should be incorporated?

\section{General requirements for a learning path specification}

The concept of learning paths (LP's) has been chosen in order to stress the specific character of lifelong learning as compared to formal, initial education. Initial education is organised in curricula designed for cohorts of learners with comparable entry levels, and delivered by formal educational institutions. Lifelong learning on the other hand is not 'organised' and preplanned like that, but develops through actions that enable a learner to attain certain competences he or she likes to or has to acquire. It is influenced by changing interests and needs both on the part of the learner and his or her situation. Lifelong learning evolves as a process of constant adaptation and change. These actions are not restricted to formal learning offered by an educational institution but will include training on the job and informal learning. For lifelong learning a learning path specification therefore must be able to describe both formal curricula and other actions that result in learning outcomes, varying from reading a book, watching a video, creating a spreadsheet, prepare a recipe to taking a course.

Thus far we can derive the following functional requirements for a learning path specification, still in very general terms:

1. A learning path specification must enable the description of actions that lead to certain learning outcomes, whether formalised in a curriculum offered by an educational institution or merely suggested by a co-learner as an appropriate way to achieve some desired learning outcomes.

This means that, like a curriculum, a learning path consists of a coherent set of actions as well as rules associated with these actions: optional and mandatory actions, and restrictions regarding the order in which the actions should be performed. Apart from the learning outcomes and actions resulting in these outcomes, the specification should enable the 
description of rules governing progress through and completion of a programme, e.g. 'for at least three out of four units a minimum grade of $X$ must have been obtained before the learner can proceed with unit Z'. In the case of informal learning a Learning Network will necessarily rely on learners' willingness to describe their informal learning paths in hindsight.

2. A learning path specification must describe these actions taking into account a decision support perspective, i.e. it must contain all information needed to support decisions on relevant actions for a learner who wants to achieve certain learning outcomes, given his or her present know-how in the field.

In image theory two phases of decision making are distinguished: screening and choice (Beach, 1997; Rundle-Thiele, Shao, \& Lye, 2005). Screening involves the selection of options taken into consideration, whereas the choice phase involves the actual decision for an option. Figure 2 schematically illustrates why a decision support perspective is needed. The figure indicates how a single competence can be acquired through various learning paths. A learning path is represented as a set of actions, subsets of actions to choose from (selections), and/or subsets of actions to be performed in a specific order (sequences). Note that an extended learning path would cover a number of competences and thus would have to combine two or more singular learning paths to one. As stated before we expect dependencies between competences to be expressed in the prerequisites of a learning path leading to a single competence or in dependencies between actions belonging to learning paths that lead to different competences.

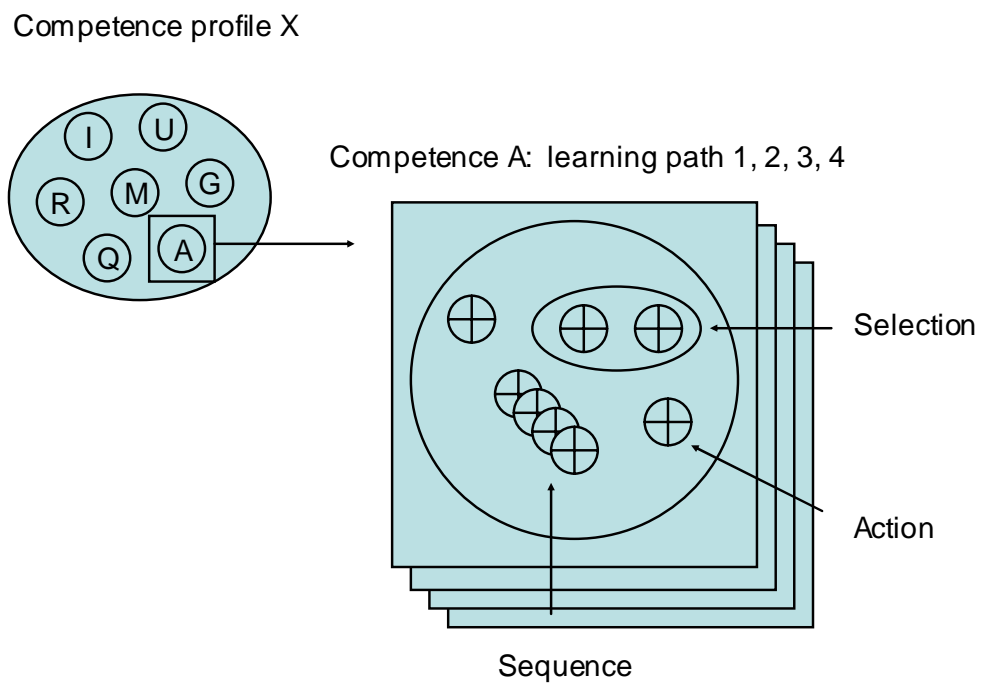

Figure 2: Learning path or competence development plan

In order to support learners in choosing a learning path from all available ones, the LP specification must facilitate identification of learning paths leading to the same learning outcomes. In this sense learning outcomes are the primary base for screening. Facilitation of further screening and final choice for an option requires that the learning path specification describes characteristics most relevant to learners' decision making. This way the specification can be used to apply filters as stated before, for instance regarding language, costs, accreditation, delivery mode, and pacing.

A complication in facilitating learners in selecting efficient and effective learning paths which is not reflected in figure 2, lies in the fact that actions might be part of a number of learning 
paths. A learner might choose a path containing actions he or she has already performed while following another learning path in the past. This means that checks have to be made for overlap between an optional learning path and the learner's learning track: the chronological description of all actions a learner has completed in the past. And of course then criteria will have to be applied to determine whether the learning outcomes which have been attained in the past can still be considered valid and up-to-date.

In summary this section has described some very general requirements for a learning path specification. These general requirements state that a learning path specification must be able to describe the structure of a learning path and all possible rules that apply to it on one hand. On the other hand the learning path specification should include those characteristics that learners apply in selecting the most appropriate learning path from the available offers. Related to this second requirement a further general requirement is that we want the specification to be in line with existing standards in the field of educational technology, most notably the IEEE Learning Object Metadata (IEEE/LOM, 2002). So we will strive to bring the selection of characteristics and their description in line with this metadata standard. The next section describes our approach in further specifying these requirements.

\section{Method}

In order to derive more precise requirements for a learning path specification we've pursued two lines of investigation.

Firstly, a review of literature on curriculum design was carried out to further investigate the structure and rules connected to a learning path. There is no standard yet in the field of curriculum design to test on suitability to describe learning paths, but there are several specifications in the field that will be analysed in this respect: IMS Learning Design (IMSLD, 2003) and the eXchanging Course-Related Information (XCRI) curriculum specification (XCRI, 2006). The IMS Learning Design specification allows defining which roles should carry out which activities, using which supportive materials and services, in order to achieve certain learning objectives. It is this 'workflow-based' approach, as opposed to simple sequencing inspired approaches (IMS-SS, 2003; SCORM, 2004), that makes it appear a suitable candidate to model flexible learning pathways (Marjanovic, 2006).

Although the XCRI project's main focus, namely exchanging course-related information, prioritises an interest in fragments of curriculum, the schema enables the description of linkages between curriculum fragments as well. The XCRI project has build on the Norwegian Course Description Metadata project (CDM, 2004) to define a vocabulary to describe course related information in a way that fits UK needs. Compared to CDM the XCRI specification offers a more generic curriculum specification object and has more options to specify curriculum structure. The vocabulary "encompasses course marketing, course quality assurance, enrolment and reporting and personal development requirements" (Stubbs \& Wilson, 2006).

Secondly, a number of recent and current initiatives aiming towards exchangeability of learning actions were analysed to see what characteristics they provide or propose to provide to learners to facilitate their decision-making. Following the recommendation to "differentiate luxury from necessity" (Hodgins et al., 2003, p. 40) we will aim to select the most important characteristics rather than strive for completeness, to then proceed to determine whether these can be described using the LOM set of metadata (IEEE/LOM, 2002).

Initiatives directed towards joint development of learning actions with the purpose of exchange have not been included in our analysis because they approach the problem of exchangeability from the other end, i.e. agreeing on formats for exchange beforehand, 
whereas we would like to facilitate exchange of learning actions which are not developed in joint agreement.

Besides numerous exchange programs exist in higher education institutions, describing opportunities and procedures either for their own students to take courses elsewhere or for foreign students to enrol in their courses. Again these are considered too specific to include them in our study.

The initiatives we studied all aim towards transparency and exchangeability at a more generic level. Different approaches can be identified which are by no means mutually exclusive, but merely represent different scopes and levels of generalisation and formalisation. We will briefly describe the different categories. Table 1 lists examples of each category.

Table 1: Examples of approaches aiming towards comparability and exchangeability

\begin{tabular}{|l|l|}
\hline \multicolumn{1}{|c|}{ Approaches } & \multicolumn{1}{c|}{ Examples } \\
\hline 1. Portals & - UCAS http://www.ucas.com/ (UK) \\
& - PLOTEUS http://europa.eu.int/ploteus/portal/home.jsp (EU) \\
& - Curriki http://www.curriki.com/ (Global) \\
\hline 2. General guidelines & - Two cycles in HE: undergraduate and graduate (EU) \\
& - Quality Assurance Agency Guidelines (UK) \\
& - European Credit Transfer and Accumulation System (EU) \\
\hline 3. Metadata applications & - CUBER (EU) \\
& - CDM (N) \\
\hline
\end{tabular}

\section{Portals}

There are quite a number of websites which list courses and programmes of various educational institutions within a country or region, across countries, or even irrespective of countries. We have selected three examples which are open for anyone to search: UCAS, which covers higher education at a national (UK) level; PLOTEUS, which, at a European level covers all levels of formal education; and Curriki, a fairly recent global initiative which is more a community than merely a portal, which aims to develop and deliver curricula through community contributors. The aim of all these initiatives is to offer learners easy access to courses and programmes. Though some directly enable learners to enrol, others link learners to the provider's website for further information and enrolment. We will compare the options these portals offer for learners to search appropriate learning actions.

\section{General guidelines}

Several initiatives have been directed towards formulating general guidelines to enable comparison of courses and programmes. Of course adoption of the undergraduate and graduate cycle in universities and higher education institutions serves that purpose on a very general level (Bologna-Declaration, 1999). The ECTS guidelines offer more concrete suggestions concerning a number of characteristics that are likely to be needed in comparing courses and programmes (CEC, 2004). The QAA guidelines for programme specifications describe a template to provide more detailed descriptions of programmes for learners (QAA, 1999). We will compare characteristics mentioned by the ECTS and QAA guidelines to the choice options offered by the portals.

\section{Metadata application}

The third category concerns initiatives applying metadata or adapting metadata standards to suit particular needs (application profiles). Application profiles may involve selecting a subset of the metadata or extending them in a prescribed way. The CUBER project is an example of an application profile of the LOM metadata standard (Lamminaho, 2000). The Course Description Metadata (CDM) project is a Norwegian initiative that "specifies the structure and semantics of key concepts used in course descriptions” (CDM, 2004, p. 3). 
As will become clear in the next sections metadata are not only relevant to provide information to learners, but also to combine actions to learning paths. Regarding both these aspects parsimony will be an important criterion in deciding upon the necessary set of characteristics for the learning path specification.

\section{Analysis}

This section describes the requirements derived respectively from the review of curriculum design literature and the analysis of initiatives aiming towards exchangeability.

\subsection{Curriculum design literature}

Building on the reasoning followed in sections 1 and 2 and further study of literature in the field of curriculum design and lifelong learning (Bligh, 1999; Colardyn \& Bjornavold, 2004; Harden, 2000; Livingstone, 1999; Marsick \& Watkins, 2001; NOCN, 2004; Ramos, Kautonen, \& Keller, 2001; Tattersall, Janssen, Van den Berg, \& Koper, 2006) the learning path specification must enable to describe learning paths taking into account the following characteristics:

- Modular composition: learning paths must be able to be built from units;

- Nested composition: learning paths must be able to be composed of other learning paths;

- Learning outcomes: learning paths are defined in terms of learning outcomes;

- Entry requirements: it must be possible to specify entry requirements for a learning path;

- Selection: it must be possible to specify which elements of a learning path are mandatory and which are optional;

- Sequencing: it must be possible to specify a fixed order in which elements of a curriculum are to be completed;

- Temporal coordination: a learning path specification must enable to express parallel programming of two or more learning actions;

- Completion: the requirements for completion of a learning path must be able to be specified;

- Conditional composition: it must be possible to specify conditions under which learning path elements are to be included or excluded;

- Substitution: learning path specification must enable description of substitution rules. Substitution rules describe which units in the learning path might be replaced and the criteria that exist regarding the substitute.

Besides the learning path specification must meet the general requirements of:

- Formality: the language must describe a route in a formal way, so that automatic processing is possible;

- Interoperability: the language must support interoperability of routes so that different support systems can share and exchange information.

Bearing in mind these requirements, we will now address the question to what extend they are met by two existing more elaborate specifications in the field of learning design (IMS-LD, 2003), and curriculum modelling (XCRI, 2006).

Using IMS-LD a learning path (Unit of Learning) can be described that consists of actions (Activities), groupings of actions (Activity Structure) or learning paths, thus enabling both modular and nested compositions. Both actions and learning paths can be related to competences/competence profiles using the element Learning objectives. A grouping of actions can be defined as either a selection or a sequence. A selection indicates that the 
referenced actions can be done in any order and through specification of a number to select that is smaller than the number of referenced actions it is possible to define a free choice range. Sequences always contain mandatory actions that have to be performed in the specified order.

Temporal coordination (parallel planning) can be specified in a number of ways. It is possible for instance to set a time-limit on a set of two actions or on each action separately. (Of course true enforcement of temporal coordination would require face-to-face actions that are planned in parallel). Regarding completion IMS-LD contains a number of elements to indicate when an action or a learning path is completed (complete activity/complete play). This might be simply because the learner considers his or her goals to have been achieved (user choice). Besides IMS-LD contains an expression language that can be used to define more complex rules for completion (e.g. 'if assignment $\mathrm{X}$ has been approved by the tutor'). The same expression language can be used to define conditional compositions (e.g. 'if learner has preference A then show action X, learning path $Y^{\prime}$ ', etcetera). Finally it is possible to express substitution rules like 'action $\mathrm{X}$ can be replaced by any other action under the condition that the substitute action either leads to the same competence, and requires a similar amount of input from the learner', by modelling the alternatives as a selection. This entails referencing concrete instances of alternatives. IMS-LD is a declarative language and can only target what is defined. Applying substitution rules in a more generic way, enabling for instance inclusion of newly developed learning actions that are in line with the rule, would require a 'meta-rule language' that can specify learning designs in an abstract way to later generate instances of learning paths using the then available learning actions which comply with that particular specification.

The XCRI specification is a generic curriculum object that can be further typed as a programme, course, module, lesson plan etcetera. Besides the curriculum object can consist of a number of these fragment types so that modular compositions can be described. Nested compositions are possible by defining fragment associations. All kinds of requirements (e.g. prerequisites and co requisites) can be described and for each curriculum fragment learning outcomes can be specified. Fragment associations are by default interpreted as sequences but can also be defined as collections with a certain order, selection range and selection criteria. Temporal coordination can be expressed through fragment associations, co requisites, and calendar events. The XCRI specification enables to specify assessments in great detail, but it is not possible to specify other ways to indicate when a course or programme can be considered completed (e.g. by user choice). Conditional compositions can be realised by specifying including and excluding requirements. Substitution can be specified in the same way as in IMS-LD: by modelling the alternatives as choice options.

Both XCRI and IMS-LD meet the general requirements of formality and interoperability: they are open specifications using the XML schema formalism.

Though both specifications provide means to specify learning paths, IMS-LD more broadly meets the requirements, because it enables to describe completion of curriculum elements in a more generic way and because it has an expression language to describe all kinds of conditional compositions.

\subsection{Initiatives to enhance exchangeability of learning actions}

In this section we describe for each category of initiatives identified in table 1, which characteristics are used or proposed to facilitate learners' choices of learning actions. Based on these descriptions and the conclusions drawn from them, we will present our own proposal 
in the conclusion section, describing a learning path model that integrates structure and characteristics of the learning path specification.

\subsubsection{Portals}

The portals selected for our analysis vary considerably in the search options they provide to learners. Table 2 lists all information (metadata) the portals provide to learners in a quick search and/or advanced search. The Curriki portal provides the most extensive metadata. This might be due to the fact that it is not just a portal but a community where both learners and teachers come to find but also add learning materials; the metadata provided in a search more or less mirror the metadata that are requested upon uploading materials.

The UCAS and PLOTEUS portals are clearly organised around courses and institutions, whereas the Curriki portal includes all types of 'instructional components'. In this respect the Curriki portal more closely reflects a Learning Network.

Table 2: Information provided to learners by different portals

\begin{tabular}{|l|c|c|c|}
\hline Metadata & $\begin{array}{c}\text { UCAS } \\
\text { (UK) }\end{array}$ & $\begin{array}{c}\text { PLOTEUS } \\
\text { (EU) }\end{array}$ & $\begin{array}{c}\text { Curriki } \\
\text { (Global) }\end{array}$ \\
\hline Course code & $\mathrm{X}$ & $\mathrm{X}$ & $\mathrm{X}$ \\
\hline Course type / level & $\mathrm{X}$ & $\mathrm{X}$ & \\
\hline Region/country & $\mathrm{X}$ & $\mathrm{X}$ & $\mathrm{X}$ \\
\hline Subject/Title & & & $\mathrm{X}$ \\
\hline Description & & $\mathrm{X}$ & $\mathrm{X}$ \\
\hline Keywords & & $\mathrm{X}$ & \\
\hline Status* (e.g. draft, final) & $\mathrm{X}$ & $\mathrm{X}$ & \\
\hline (Link to) institution* & & $\mathrm{X}$ & \\
\hline Attendance type & & & $\mathrm{X}$ \\
\hline Language & & & $\mathrm{X}$ \\
\hline Resource type* (e.g. url, image, text) & & & $\mathrm{X}$ \\
\hline Publish date* & & & $\mathrm{X}$ \\
\hline Contributor * & & & $\mathrm{X}$ \\
\hline $\begin{array}{l}\text { Instructional component* (e.g. lesson } \\
\text { plan/presentation/course) }\end{array}$ & & & $\mathrm{X}$ \\
\hline $\begin{array}{l}\text { Learning Resource type: Comprehensiveness } \\
\text { (individual asset/course/curriculum) }\end{array}$ & & $\mathrm{X}$ \\
\hline $\begin{array}{l}\text { Framework alignment (e.g. Master } \\
\text { Framework - Science - Technology) }\end{array}$ & & & \\
\hline Licence & & & \\
\hline Right holder & & & \\
\hline
\end{tabular}

\footnotetext{
* The metadata indicated by an asterix contain information that is subsequently provided, rather than used as basis for a search.
}

The Curriki portal offers direct access to the resources for free, whereas the UCAS and PLOTEUS portals link to institutional websites where the learner can find more information. This makes it necessary for the Curriki portal to offer more information on the resources. However, information like publish date, contributor, licence, and right holder don't seem that relevant to someone who's searching for learning actions that will help him or her attain certain learning outcomes. In this respect and also in view of initiatives described in the next sections, it is remarkable that all three portals focus on subject as the central search option, rather than learning outcomes.

\subsubsection{General guidelines}

The Quality Assurance Agency Guidelines for preparing program specifications state that “A good programme specification will improve student understanding of how and when learning 
occurs, and of what is being learned, and thereby inform reflection upon personal learning, performance and achievement, and subsequent planning for educational and career development." (QAA, 1999, p. 3).

The information which the QAA guidelines suggest will normally be included in a programme specification is:

- $\quad$ awarding body/institution;

- teaching institution (if different);

- details of accreditation;

- name of the final award;

- programme title;

- UCAS code;

- aims of the programme;

- relevant subject benchmarks statements and other reference points used to inform programme outcomes;

- programme outcomes: knowledge and understanding; skills and other attributes;

- teaching, learning and assessment strategies to enable outcomes to be achieved and demonstrated;

- programme structures and requirements, levels, modules, credits and awards;

- date at which the programme specification was written or revised.

The guidelines state that in addition institutions might want to include criteria for admission to the programme, information about assessment regulations, indicators of quality, particular support for learning and methods for evaluating and improving the quality and standards of learning.

The European Credit Transfer and Accumulation System (CEC, 2004) aims to make study programmes easy to compare. It is based on the (estimated) average student workload required to achieve the objectives of a programme of study and its constituent parts. ECTS can be used for accumulation within an institution and for transfer between institutions. Its basic parameters - workload and learning outcomes - can also be applied to self-study and work experience, thus making it a suitable instrument in the context of lifelong learning as well. ECTS starts from the principle that the workload of a full-time student during one academic year (1500-1800 hours) equals 60 credits. One credit thus equals about 25 to 30 hours of work. Credits are allocated to a study programme and its constituent parts based on a realistic estimation of the average student workload that is required to achieve the learning outcomes. The ECTS Users' Guide describes learning outcomes as "sets of competences, expressing what the student will know, understand or be able to do after completion of a process of learning, whether long or short. (..) Learning outcomes specify the requirements for award of credit.” (CEC, 2004, p. 12).

The ECTS Information Package and Diploma Supplement define items to be described in order to make study programs easy to understand and compare. These items are very similar to those proposed by the QAA programme specification guidelines. Gosling (2001) strongly defends the use of credit and level as descriptors of curricula components to increase flexibility in support of lifelong learning. He goes on to argue that the use of "qualification level" as an indicator for level is too strongly related to the status quo - existing qualifications and national systems - to increase flexibility. Key concepts of a credit-based curriculum mentioned by Gosling are: credit (a means of quantifying learning), level (an indicator of relative demand; complexity; depth of study and learner autonomy), level descriptors, 
learning outcomes, assessment criteria, notional learning time, module or unit and Assessment of Prior Learning (APL).

\subsubsection{Metadata applications}

The CUBER system is designed to be a search engine or broker system that enables students to search for courses from a number of higher education institutions (Pöyry, Pelto-Aho, \& Puustjärvi, 2002). The goals of the system are (amongst others) to enable comparison of courses from different providers and to find the best matches to one's personal educational goals; to provide information on how courses are integrated and to make it possible to generate a complete curriculum plan; and to provide information on degrees and (international) recognition of degrees and certificates.

As the project aimed towards interoperability, the metadata specification of CUBER was based on the (then) emerging LOM standard. Interestingly a questionnaire was used to gather information about courses from each partner country. Extensions were made to the LOM metadata schema to enable descriptions of begin, end, phase, ECTS credits, interests, studyload, learning objectives, examination method, teaching method, study guidance and provider (Lamminaho, 2000). Regarding requirements (part of the technical metadata in the LOM) a distinction was made between technical requirements, skills and previous studies and certificates.

A separate study was directed towards finding out which parameters and rules appear to guide decisions regarding course acknowledgement (i.e. parameters and rules used in comparing two courses for exchangeability), with the aim to include these parameters into the CUBER metadata model (Ramos, Kautonen, \& Keller, 2001). The parameters used in course comparison were: credits, content, extent (detail of content), difficulty, and examination method.

The CDM project intends to facilitate description and exchange of information about course units, standardization of course unit descriptions, establishment of national and international course catalogues, course portals and other student services. Although the focus is on courses, CDM groups metadata in four types:

1. Organisation unit type represents an organisational unit that provides study programs and courses.

2. Program type contains the description of a study program, which can have a hierarchical structure with subordinate study programs.

3. Course type. A course is defined as "a complete unit of instruction that provides the learner with the knowledge or skills required for competence in a subject matter".

4. Person type contains the description of a person with the focus on providing contact information.

The CDM metadata to describe programs are similar to the items defined by ECTS and QAA, though both the latter go into more detail regarding qualification, accreditation and quality indicators. Unlike other initiatives, the CDM specification includes 'target group' as a program characteristic and also distinguishes between formal and recommended prerequisites.

\subsubsection{Comparing the approaches}

Different initiatives clearly place different accents in describing educational offerings, depending on different aims and backgrounds. Whereas PLOTEUS and CUBER for instance seem more strongly driven by a wish to compare and exchange educational offerings, CDM seems more strongly inspired by a "provider perspective” while QAA and ECTS share a wish 
to accurately cover prospectus information and information pertaining to awarding and accrediting institutions and quality procedures.

Facilitating lifelong learning however requires that the focus of attention is on the learner and his/her learning needs. To enable learners' choices it will be more important to indicate whether or not a learning path leads to formal recognition, than to describe which institution it is awarded by. We believe that quite a lot of this more detailed information could be suitably offered by linking to a provider's website. Moreover learners will need to have planning information and information on all kinds of possible prerequisites, in order to decide whether a learning path is suitable to their needs. Some of the initiatives investigated describe quite a number of planning aspects in parallel (study load in weeks as well as typical learning time for instance). We propose to use a minimum set of start date, end date and total workload. Together with information on contact hours we believe this to suffice for learners or software agents to decide whether the learning path complies with their personal schedule. Total workload is also considered to suffice to quantify the learning involved. Though ECTS seems widely adhered to in European projects, we propose to use the more general term 'workload' or 'typical learning time' (as used in LOM), because the credit system is only known in Europe and EC's can be easily derived from the workload in hours.

As to level indicators, the first sections of this paper already revealed how we consider levels to be intricately connected to competences (learning outcomes). Competences and proficiency levels are guiding principles in structuring and describing learning paths. All other types of level descriptors might be used ('bachelor' 'graduate') but they necessarily need to be elaborated in terms of learning outcomes in order to make them meaningful. This is why we believe these general level indicators to be superfluous ultimately. Besides proficiency levels related to competences are more suitable as level indicators in the realm of lifelong learning because they exceed these 'school career' level indicators.

\section{Conclusions}

Figure 3 represents a model of the learning path specification we propose. The figure maps the Learning Networks and learning path terminology on IMS-LD elements (between brackets) and describes further characteristics already provided by IMS-LD (in the model these are presented as attributes, whereas in fact they are either elements or attributes).

A learning path leads to the acquirement of one or more competences or to a competence profile. The learning path consists of one or more actions, clusters of actions or learning paths. These actions, and/or clusters and/or learning paths are presented in a certain structure, describing the overall learning flow. The learning flow may depend on certain circumstances as expressed in 'if-then' rules pertaining for instance to learner preferences or the way the learning process evolves.

In other words a learning path basically describes a structure of one or more actions, clusters of actions or learning paths, in a way that explicates restrictions and degrees of freedom for the learner. Restrictions and degrees of freedom are not only defined through structuring principles describing optional and required elements or through rules, but can also be reflected in metadata describing the learning path or its constituting parts, e.g. delivery mode, teaching place, contact hours etc. Table 3 provides a more detailed description of the classes of the learning path model and their attributes, as well as the additional metadata we propose to facilitate learner choice. 


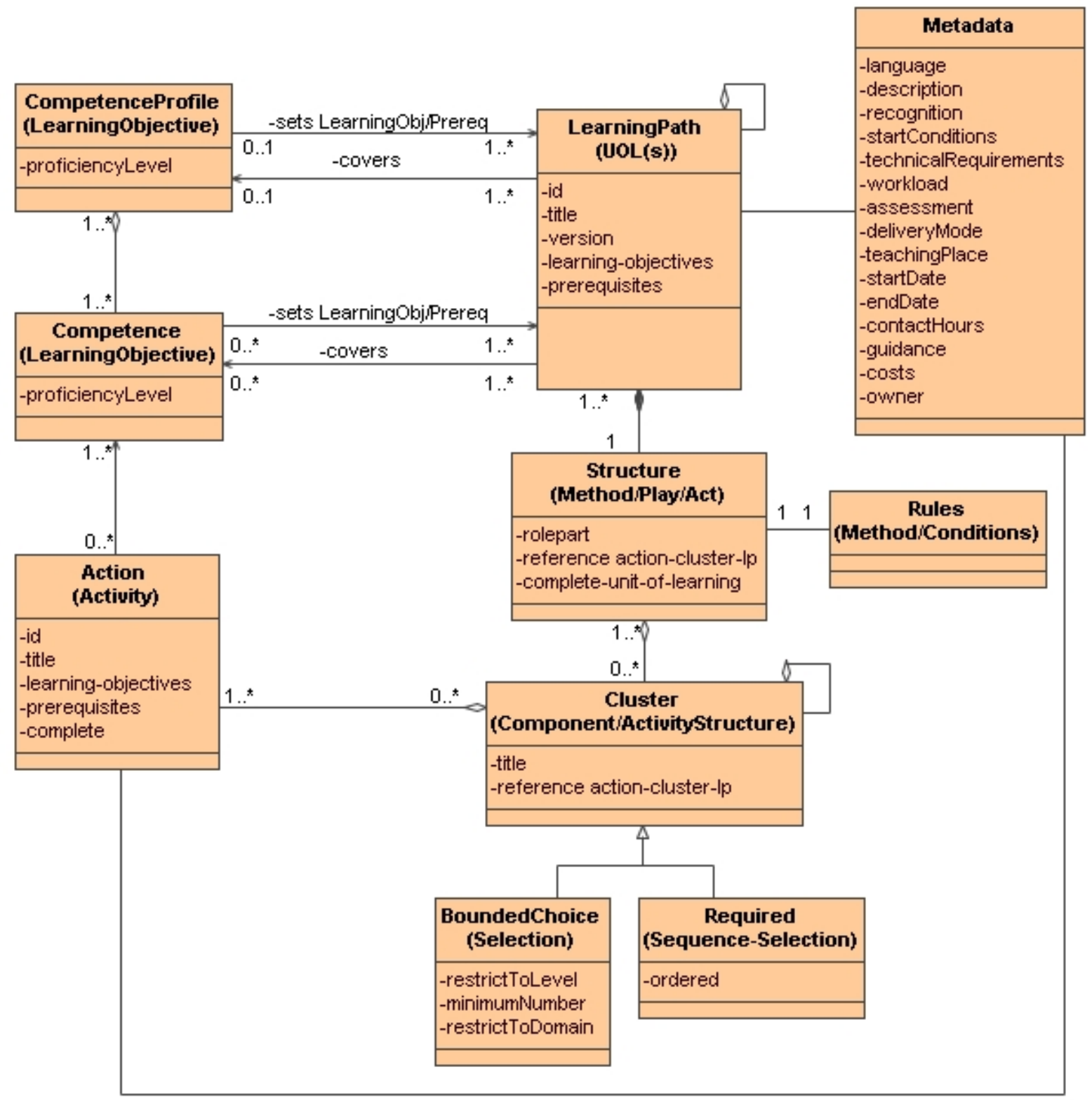

Figure 3: Learning Path model

Table 3 Classes and attributes of the Learning Path model

\begin{tabular}{|l|l|}
\hline Class /attribute & Description \\
\hline LearningPath & $\begin{array}{l}\text { A Learning path describes the actions a learner has to perform in order to attain } \\
\text { a competence or competence profile. }\end{array}$ \\
\hline identifier & An identifier that can be used to refer to the learning. \\
\hline title & $\begin{array}{l}\text { Title of the learning path equals the title of the action when the learning path } \\
\text { consists of a single action. }\end{array}$ \\
\hline version & $\begin{array}{l}\text { Versioning will be necessary to allow for updates of learning paths and enable } \\
\text { identification of specific versions. }\end{array}$ \\
\hline learning-objectives & Describe the intended outcome for learners. \\
\hline prerequisites & $\begin{array}{l}\text { Describes the entry-requirements for learners in terms of competences } \\
\text { (knowledge, skills, and attitudes). It still remains to be seen whether and how } \\
\text { the distinction between formal and recommended prerequisites must be made. }\end{array}$ \\
\hline
\end{tabular}




\begin{tabular}{|c|c|}
\hline $\begin{array}{l}\text { CompetenceProfile/ } \\
\text { Competence }\end{array}$ & $\begin{array}{l}\text { A competence profile describes the set of competences a person has to master } \\
\text { in order to perform adequately in a particular job or function. Competence is } \\
\text { defined as the ability of an actor to act effectively and efficiently in an } \\
\text { ecological niche (e.g. occupation, hobby, sport etc). }\end{array}$ \\
\hline proficiencyLevel & $\begin{array}{l}\text { Competence profiles and competences can have one or more proficiency levels, } \\
\text { i.e. levels of mastery (novice, expert, etc.). }\end{array}$ \\
\hline Action & $\begin{array}{l}\text { Any activity performed with the aim to develop a competence. Actions have } \\
\text { the same attributes as learning paths. }\end{array}$ \\
\hline identifier, title etc & See under: Learning Path \\
\hline complete & $\begin{array}{l}\text { Contains a choice of elements to specify when an activity is completed, e.g. } \\
\text { when certain task has been completed, by user choice. }\end{array}$ \\
\hline Structure & $\begin{array}{l}\text { The structure defines the 'work/learning flow' of a learning path and its } \\
\text { constituent parts. }\end{array}$ \\
\hline $\begin{array}{l}\text { rolepart } \\
\text { reference }\end{array}$ & $\begin{array}{l}\text { The structure is defined by linking roles (learner, teacher, tutor, assessor) to } \\
\text { actions, clusters of actions or learning paths by referring to them. }\end{array}$ \\
\hline $\begin{array}{l}\text { Complete-unit-of- } \\
\text { learning }\end{array}$ & $\begin{array}{l}\text { Specifies when a learning path can be considered completed, e.g. upon passing } \\
\text { examination, by user choice, on a time-limit. Without this element completion } \\
\text { is 'unlimited'. }\end{array}$ \\
\hline Rules & $\begin{array}{l}\text { Rules can be used to specify whether some actions, clusters or learning paths } \\
\text { should be included or excluded under certain conditions. }\end{array}$ \\
\hline Cluster & $\begin{array}{l}\text { A cluster is used to group actions (and/or clusters and/or learning paths) that } \\
\text { are somehow related, for instance because they compose a set a learner can } \\
\text { choose from, or because they have to be studied in a particular order. See } \\
\text { below. }\end{array}$ \\
\hline title & A header for the grouping of actions, clusters, and/or learning paths. \\
\hline BoundedChoice & $\begin{array}{l}\text { Bounded choice describes a cluster of actions, clusters and/or learning paths a } \\
\text { learner can choose from. }\end{array}$ \\
\hline restrictToLevel & $\begin{array}{l}\text { Specifies that the cluster should only contain elements that relate to a certain } \\
\text { level. }\end{array}$ \\
\hline minimumNumber & $\begin{array}{l}\text { Specifies the number of elements from the given set that the learner has to } \\
\text { minimally complete. }\end{array}$ \\
\hline restrictToDomain & $\begin{array}{l}\text { Specifies that the cluster should only contain elements that relate to a certain } \\
\text { domain. }\end{array}$ \\
\hline Required & $\begin{array}{l}\text { A cluster of actions, clusters, and/or learning paths a learner has to complete } \\
\text { either in a specific order (sequence) or in a free order (selection) to complete } \\
\text { the learning path. }\end{array}$ \\
\hline ordered & $\begin{array}{l}\text { Specifies whether or not the elements of the cluster have to be completed in the } \\
\text { given order. }\end{array}$ \\
\hline Metadata & $\begin{array}{l}\text { Characteristics of the learning path which are relevant to learner's screening } \\
\text { and eventual choice of a learning path. }\end{array}$ \\
\hline language & $\begin{array}{l}\text { Specifies which language(s) the learner needs to know to follow the learning } \\
\text { path. }\end{array}$ \\
\hline description & General description of the learning path. \\
\hline recognition & $\begin{array}{l}\text { This attribute only states whether completion of the learning path leads to a } \\
\text { formal recognition (diploma/certificate). (N.B.: this is not the same as } \\
\text { distinguishing between formal, non-formal, and informal learning. Formal } \\
\text { learning not necessarily results in formal recognition). }\end{array}$ \\
\hline startConditions & $\begin{array}{l}\text { Several entry or start requirements may hold apart from the required } \\
\text { competences (prerequisites) e.g. a specific diploma or course certificate, a } \\
\text { minimum age or minimum average grade. Other conditions might relate to } \\
\text { practical or pedagogical issues: a minimum number of enrolments. }\end{array}$ \\
\hline technicalRequirements & $\begin{array}{l}\text { Specifies technical equipment and tools a learner needs in order to take this } \\
\text { path. }\end{array}$ \\
\hline workload & The total workload in hours. \\
\hline assessment & $\begin{array}{l}\text { Describes which formative and/or summative assessments are in place to } \\
\text { determine to what extend the learner has attained the competence. }\end{array}$ \\
\hline deliveryMode & $\begin{array}{l}\text { Describes the modes used for delivery of the learning path, e.g. distance } \\
\text { learning using all kinds of media, face-to-face teaching etc. We expect this } \\
\text { attribute to be important for initial selection (screening) of relevant learning }\end{array}$ \\
\hline
\end{tabular}




\begin{tabular}{|l|l|}
\hline & paths to choose from. \\
\hline teachingPlace & $\begin{array}{l}\text { In case a learning path requires face-to-face meetings the learner needs to know } \\
\text { where they take place in order to decide whether this suits him/her. }\end{array}$ \\
\hline startDate & $\begin{array}{l}\text { In case there are fixed starting dates for a learning path, for instance in a } \\
\text { semester schedule, this information is needed to see whether it fits the learner's } \\
\text { needs and schedule. This attribute will be empty in case learners are free to } \\
\text { start whenever they want. }\end{array}$ \\
\hline endDate & See startDate. \\
\hline contactHours & $\begin{array}{l}\text { Contact hours informs on the hours the learner is expected to attend (virtual) } \\
\text { meetings. Teaching place, workload, start date and end date together still don't } \\
\text { suffice to provide the learner with complete picture of the flexibility of the } \\
\text { learning path in terms of time, place and pace. }\end{array}$ \\
\hline guidance & $\begin{array}{l}\text { Describes what support is available to learners taking the learning path } \\
\text { (tutoring, counselling, helpdesk...). }\end{array}$ \\
\hline costs & Specifies costs for enrolment and additional expenses (books, tools, etc.) \\
\hline owner & $\begin{array}{l}\text { Links to a webpage containing more detailed information on the owner of the } \\
\text { learning path (person or institution), enrolment, accreditation regulations, } \\
\text { facilities for special needs students, contact information etc. }\end{array}$ \\
\hline
\end{tabular}

\section{Discussion}

The learning path model presented in this paper is a first step towards a learning path specification. Several issues are still open. Firstly, the LOM metadata set does not have elements describing planning information, assessment or study guidance for instance. Somehow these characteristics will have to be included in the learning path specification. The model will be elaborated into a more detailed information model. In this process it will also be decided more precisely how the characteristic identified in the model can be expressed through IMS LD elements and attributes or through (extensions to) LOM metadata.

Secondly, competences and competence profiles are dynamic entities. They may change over time due for instance to technological developments in a profession. Besides, once acquired they may require regular updates even if the competences themselves have not changed, simply because competences can grow weaker or decline due to lack of practice. Changes in competences and competence profiles can be expressed through versioning and a period of validity can be defined at a personal level. How changes of competences and competence profiles will affect learning paths and whether the version attribute of learning paths suffice to indicate these changes is not entirely clear.

Finally, there's the issue of adding metadata to actions and learning paths: who will do it and will it be done? While many authors stress the advantages of adding metadata over free text search, they also express concerns regarding the accuracy it requires and the costs involved (Hirvasniemi \& Öörni, 2001; Lamminaho, 2000; Pöyry, Pelto-Aho, \& Puustjärvi, 2002). For extended learning paths some metadata might be automatically derived or calculated from the metadata of the constituting actions: start and end dates for instance, but also workload, delivery mode, and costs. However that still means these metadata will have to be available at the lower level of actions. A solution might be found in automated metadata generation. Possibilities for that are being investigated and some promising results have been achieved (Cardinaels, Meire, \& Duval, 2005).

The learning path model proposed in this article is based on a literature study as well observation of current practices aiming to facilitate learner choice and to enhance comparability of learning actions. These observations have been reflected upon from a lifelong learning perspective and striving for parsimony. Further empirical evidence will have to be gathered to confirm whether the specification is sufficiently elaborate to describe all kinds of learning actions. To that end the specification will be tested on a variety of actual 
formal, non-formal, and informal learning paths (e.g. can it describe the training programme of company X, can it describe the masters programme of university $\mathrm{Y}$, the learning path of $\mathrm{Z}$ ). Once that has been established the specification will be tested in a pilot where it will be used to facilitate navigational support. In this pilot it will become clear whether the specification is balanced in the sense that it contains sufficient information to enable learners to decide upon a suitable learning path.

\section{Acknowledgement}

The work on this paper has been sponsored by the TENCompetence Integrated Project that is funded by the European Commisson's $6^{\text {th }}$ Framework Programme, priority IST/Technology Enhanced Learning. Contract 027087 (www.tencompetence.org).

\section{References}

Adam, S. (2001). A Pan-European Credit Accumulation Framework - Dream or Disaster? Higher Education Quarterly, 55(3), 292-305.

Beach, L. R. (1997). The Psychology of Decision Making: People in Organizations. Newbury Park, CA: Sage.

Bligh, J. (1999). Curriculum design revisited. Medical Education, 1999(33), 082-085.

Bologna-Declaration. (1999). Retrieved 2006-01-25, from http://www.bolognaberlin2003.de/pdf/bologna_declaration.pdf

Cardinaels, K., Meire, M., \& Duval, E. (2005). Automating Metadata Generation: the Simple Indexing Interface. Paper presented at the 14th international conference on World Wide Web, May 10-14, 2005, Chiba, Japan.

CDM. (2004). A Specification of Course Description Metadata. Proposal 20. Oct. 2004. Retrieved 2006-01-30, from http://cdm.utdanning.no/cdm/cdm2.0.1/doc/courseDesc201004.pdf

CEC. (2001). Communication from the Commission: making a European area of lifelong learning a reality (No. 678, final of 21.11.01). Brussels: Commission of the European Communities.

CEC. (2004). Commission of the European Communities: ECTS Users' Guide: European Credit Transfer and Accumulation System and the Diploma Supplement. Brussels: Directorate General for Education and Culture.

Colardyn, D., \& Bjornavold, J. (2004). Validation of Formal, Non-formal and Informal Learning: policy and practices in EU Member States. European Journal of Education, 39(1), 69-89.

González, J., \& Wagenaar, R. (2003). Tuning Educational Structures in Europe. Final Report Phase One. Retrieved 2006-02-16, from http://tuning.unideusto.org/tuningeu/

Gosling, D. (2001). Lost Opportunity: What a Credit Framework Would Have Added to the National Qualification Frameworks. Higher Education Quarterly, 55(3), 270-284.

Harden, R. M. (2000). The integration ladder: a tool for curriculum planning and evaluation. Medical Education, 2000(34), 551-557.

Hirvasniemi, S., \& Öörni, K. (2001). Educational Information in the Web: Discussing the Metadata Requirements for a Web Service Guiding Citizens' Education. Paper presented at the International Conference on Dublin Core and Metadata Applications, Tokyo, Japan.

Hodgins, W., Tomás Ramirez, G., Brown, J., Dodds, P., Christensen, M., Miller, B., et al. (2003). Making Sense of Learning Specifications \& Standards: A Decision Maker's 
Guide to their Adoption. 2nd Edition: The MASIE Center e-Learning CONSORTIUM.

IEEE/LOM. (2002). Standard for Learning Object Metadata. Learning Technologies Standards Committee of the IEEE 148.41.21. Retrieved 2006-06-12, from http://ltsc.ieee.org/wg12/files/LOM_1484_12_1_v1_Final_Draft.pdf

IMS-LD. (2003). IMS Learning Design Information Model. Version 1.0 Final Specification Retrieved 2004-02-27, 2004, from http://www.imsglobal.org/learningdesign/index.cfm

IMS-SS. (2003). IMS Simple Sequencing Best Practice and Implementation Guide. from http://www.imsglobal.org/simplesequencing/ssv1p0/imsss_bestv1p0.html

Karran, T. (2004). Achieving Bologna Convergence: is ECTS Failing to Make the Grade? Higher Education in Europe, $X X I X(3)$.

Koper, R., Rusman, E., \& Sloep, P. (2005). Effective Learning Networks. Lifelong Learning in Europe, 1, 18-27.

Koper, R., \& Tattersall, C. (2004). New directions for lifelong learning using network technologies. British Journal of Educational Technology, 35(6), 689-700.

Lamminaho, V. (2000). Metadata Specification: Forms, Menus for Description of Courses and All Other Objects CUBER project: Deliverable D3.1. Retrieved 2006-06-03, from http://www.cuber.net/web-v1/publications/cuber-d3-1.pdf

Livingstone, D. W. (1999). Exploring the Icebergs of Adult Learning: Findings of the First Canadian Survey of Informal Learning Practices. NALL Working Paper No 10 Retrieved 2007-04-24, from www.nall.ca/res/10exploring.pdf

Marjanovic, O. (2006). Using process-oriented, sequencing educational technologies: some important pedagogical issues. Computers in Human Behavior. doi:10.1016/j.chb.2006.08.005

Marsick, V. J., \& Watkins, K. E. (2001). Informal and Incidental Learning. New Directions for Adult and Continuing Education(89).

NOCN. (2004). NOCN Credit and Qualification Framework Technical Specification General. Retrieved 2007-03-06, from http://www.nocn.org.uk/quals/CQF_Forms/CQF_technical/NOCN\%20CQF\%20\%20Technical\%20Specification\%20-\%20General\%20-\%20V2.pdf

PLOTEUS. (2006). Portal on Learning Opportunities throughout the European Space. Retrieved 19-01-2006, from http://europa.eu.int/ploteus/portal

Pöyry, P., Pelto-Aho, K., \& Puustjärvi, J. (2002). The Role of Metadata in the CUBER System. Paper presented at the SAICSIT 2002 South African Institute of Computer Scientists and Information Technologists on Enablement through Technology, Port Elizabeth South Africa.

QAA. (1999). Guidelines for preparing programme specifications: The Quality Assurance Agency for Higher Education. Retrieved 2006-01-24, from http://www.qaa.ac.uk/academicinfrastructure/programSpec/progspec0600.pdf

Ramos, E. G., Kautonen, H., \& Keller, J. (2001). Intermediate Report Including Revision of Meta Data. CUBER project: Deliverable D9.1. Retrieved 2006-06-03, from http://www.cuber.net/web-v1/publications/cuber-dg-1.pdf

Rundle-Thiele, S., Shao, W., \& Lye, A. (2005). Computer Process Tracing Method: Revealing Insights Into Consumer Decision-Making. Paper presented at the Australian and New Zealand Marketing Academy Conference (ANZMAC). Retrieved 2006-0705, from http://smib.vuw.ac.nz:8081/WWW/ANZMAC2005/cd-site/pdfs/3Consumer-Beh/3-Rundle-Thiele.pdf

SCORM. (2004). Sequencing and Navigation. 3rd Edition. Retrieved 2006-09-09, from https://www.adlnet.gov/downloads/311.cfm 
Stubbs, M., \& Wilson, S. (2006). eXchanging Course-Related Information: a UK serviceoriented approach. Paper presented at the International Workshop in Learning Networks for Lifelong Competence Development, TENCompetence Conference, Sofia, Bulgaria.

Tattersall, C., Janssen, J., Van den Berg, B., \& Koper, R. (2006). Modelling routes towards learning goals. Campus-Wide Information Systems, 23(5), 312-324.

TENCompetence, I. P. (2005). TENCompetence. Building the European Network for Lifelong Competence Development. Retrieved 2006-01-05, from http://www.tencompetence.org/

XCRI. (2006). eXchanging Course-Related Information. Retrieved 2006-10-16, from http://www.elframework.org/projects/xcri 